\title{
Análise da produção escrita em uma prova de Matemática em Fases
}

André Luis Trevisan

Regina Luzia Corio de Buriasco

\begin{abstract}
Resumo
Neste artigo, apresentamos um estudo envolvendo a utilização de uma prova em fases em aulas de Matemática, em uma turma do Ensino Médio. Tratase de uma alternativa ao formato tradicional da prova escrita, uma tentativa de tornar a avaliação integrada ao próprio ato de ensino. Apresentamos a análise da produção escrita dos estudantes em uma das questões dessa prova, antes e após um momento de intervenção. Além de possibilitar compreender diferentes aspectos da produção matemática dos estudantes, essa análise forneceu elementos que possibilitaram reorientar a própria prática pedagógica.
\end{abstract}

Palavras-chave: Educação Matemática Realística, avaliação da aprendizagem, análise da produção escrita, prova em fases.

\section{Abstract}

\section{Analysis of a written production in a Mathematics Stage Test}

In this article, we present a study involving the use of a stage test in Mathematics classes of High School. This is an alternative to the traditional format of the written test, an attempt to make the integrated assessment to the act of teaching itself. We present the analysis of written production of students in one question, before and after a moment of intervention. Besides enabling to understand different aspects of mathematical output of students, this analysis provided evidence that enabled redirect own pedagogical practice.

Keywords: Realistic Mathematics Education, assessment in school mathematics, analyses of written production, stage task.

\section{Introdução}

No cotidiano escolar, a avaliação é parte do trabalho dos professores e tem por objetivo proporcionar-Ihes subsídios para as decisões a serem tomadas a respeito do processo educativo. Entretanto, conforme apontam Hadji (1994), Van Den Heuvel-Panhuizen (1996), De Lange (1999), Barlow (2006), a avaliação muitas vezes tem servido apenas como instrumento de medida e de classificação que, ao término de uma etapa, "informa" aos estudantes um resultado acima ou abaixo da média estabelecida. Na crítica que esses autores fazem, a avaliação no ambiente escolar tem sido tomada como uma simples verificação do rendimento escolar, e seus resultados como uma informação quantificada e traduzida na nota final do estudante, evidenciando sua função de controle dos conhecimentos.

DOI: Em andamento. 
De encontro a essa perspectiva, entendemos que a avaliação deva tornar-se um instrumento de formação, fazendo-se presente no processo educativo tanto como meio de diagnóstico dos processos de ensino e de aprendizagem quanto como instrumento de investigação da prática pedagógica. Corroborando essa ideia, Barlow (2006) aponta que a avaliação escolar deve ter por objetivo "ajudar a otimizar seus próprios recursos [do estudante]" e que "não terá utilidade se não for assimilada, se não servir de ferramenta para que ele próprio construa seu saber" (BARLOW, 2006, p. 70).

Para De Lange (1999), é necessário entender a real função da avaliação, uma vez que ela pode revelar informações relevantes sobre os problemas dos estudantes ao aprender, os seus progressos e o nível de formalidade em que estão operando, de modo que os professores, reconhecendo essa função, possam adaptar suas estratégias de ensino para atender às necessidades dos estudantes. Ainda de acordo com esse autor, uma ressignificação no processo de avaliação em sala de aula pode trazer uma forte contribuição para que de fato ocorra a aprendizagem.

Para tornar a avaliação parte dos processos de ensino e de aprendizagem, deve-se exercêla ao longo de toda ação de formação, torná-la permanente, passar da meta de identificar se os estudantes adquiriam conhecimentos que Ihes foram propostos para a meta de preparar, orientar, aperfeiçoar a ação do estudante e do próprio professor. Torná-la, portanto, formativa.

Adotar essa perspectiva formativa da avaliação leva-nos a encará-la como integrada à ação de formação, incorporada ao próprio ato de ensino. Sua principal função é

\section{"Contribuir para melhorar a aprendizagem em curso, informando o professor sobre as condições em que está a decorrer essa aprendizagem, e instruindo o aprendente sobre o seu próprio percurso, os seus êxitos e as suas dificuldades (HADJI, 1994, p. 63)."}

Nesse sentido, compreender a avaliação e executá-la como um projeto intencional e planejado no cotidiano das aulas implica, entre outras coisas, pensar os instrumentos e defini-los de acordo com as possibilidades teórico-metodológicas que oferecem para avaliar. A prova escrita, presente em "peso" nas aulas de Matemática, pode ser interpretada e vista tanto como um instrumento de certificação quanto como um instrumento de orientação, dependendo do uso que se faça dela. Torna-se imprescindível, portanto, que o professor explore as potencialidades desse instrumento e apresente alternativas aos formatos tradicionais de provas escritas.

A literatura apresenta-nos a prova em duas fases como uma prova escrita realizada em dois momentos: uma primeira etapa na sala de aula, com tempo limitado, e uma segunda fase, num tempo maior, em geral, a ser feita em casa. Para De Lange (1987), a prova em duas fases oportuniza aos estudantes refletir a respeito de seu próprio trabalho: depois de resolvida pela primeira vez na escola, a prova é corrigida e comentada pelo professor e, posteriormente, 
devolvida ao estudante para o trabalho adicional em casa. Neste artigo, propomo-nos apresentar dados de um estudo envolvendo a utilização de uma prova escrita em fases em aulas de Matemática, bem como analisar a produção escrita dos estudantes em uma das questões dessa prova, antes e após um momento de intervenção.

Entendemos que a proposta de utilização de uma prova em fases apresenta-se como uma estratégia para implementação da avaliação como prática de investigação, uma vez que possibilita interpretar e refletir sobre os processos de ensino e de aprendizagem, proporcionando indicativos para o "desenvolvimento de capacidades matemáticas dos estudantes e para a prática pedagógica dos professores" (VIOLA dos SANTOS; BURIASCO; CIANI, 2008, p.37).

Nossa proposta de utilização desse instrumento foi desenvolvida à luz da abordagem conhecida como Educação Matemática Realística (RME, do inglês Realistic Mathematics Education). Para Hans Freudenthal, matemático holandês precursor desse movimento, a avaliação não é vista no sentido estrito de simplesmente determinar o que o estudante aprendeu, mas em considerar diferentes aspectos, tais como: a importância do papel desempenhado pelo professor, o direito do estudante saber o que aprendeu e quais os procedimentos cabíveis ao professor no sentido de contribuir para a efetiva aprendizagem do estudante. Freundenthal $(1973,1979)$ considerava a avaliação como parte do processo de desenvolvimento educacional e pedagógico.

Ao discutir algumas das características que devem permear o processo de avaliação, Van Den Heuvel-Panhuizen (1996) aponta que, para tornar uma prova escrita mais informativa, deveria se oferecer ajuda ao estudante, de modo que a sua reação a ajuda oferecida fosse observada. Assim, ao invés de manter uma abordagem estática focada naquilo que o estudante é capaz de produzir em um dado momento, em RME é considerado mais importante descobrir o que o estudante pode aprender. Nesse sentido, uma ajuda oferecida em provas possibilita fazer alguma inferência sobre qual será o próximo passo no desenvolvimento do estudante.

\section{Procedimentos metodológicos}

O estudo foi desenvolvido junto a uma turma de segundo ano do Ensino Médio, cujo primeiro autor foi professor ao longo do ano de 2010. A prova foi elaborada com base no planejamento do primeiro semestre e contemplou tópicos referentes ao tema Trigonometria. Foram selecionadas 28 questões provenientes de listas de exercícios e provas aplicadas em anos anteriores. Foi organizada para ser resolvida em seis etapas, sendo que a primeira, logo no primeiro dia de aula daquele semestre, consistia na leitura da prova e eventual resolução de alguma questão. Nesse dia, os estudantes dispuseram de 25 minutos e, nas cinco subsequentes, um tempo de 100 minutos. No primeiro dia, nossa intenção não necessariamente era que os estudantes resolvessem as questões, mas apenas "tomassem nota" do que seria prova naquele

DOI: Em andamento. 
bimestre (mesmo porque as questões contemplavam conteúdos que ainda seriam explorados em aula). Não havia indicação de quais questões deveriam ser resolvidas a cada fase, de modo que os próprios estudantes deveriam ser capazes de saber qual resolver, podendo alterar as resoluções, nas etapas subsequentes, sempre que julgassem necessário.

Metade das questões da prova envolvia conteúdos que constavam no planejamento para os meses de março e abril (primeiro bimestre) e o restante para maio e junho (segundo bimestre). Foram incluídas também três questões que contemplavam tópicos de anos anteriores, uma delas logo entre as primeiras, como uma possível forma de motivação para a resolução de questões já na primeira fase.

Quanto à formatação, a prova continha uma folha de rosto na qual constavam: o nome da disciplina, do professor, um espaço para o nome do estudante e as instruções sobre como essa seria desenvolvida. Nas dez páginas que compunham a prova foi deixado espaço entre cada questão, de modo que o estudante pudesse fazer a sua resolução logo após o enunciado, e, o espaço ao lado, na página seguinte, foi destinado às correções ou modificações em etapas posteriores à apresentação da primeira resolução.

Entre a terceira e a quarta fases os estudantes receberam um feedback das questões resolvidas até então. Ao lado de cada resolução, apresentamos um questionamento, independentemente de estar correta ou incorreta, de modo que, ao tomar contato com ele, o estudante pudesse refletir a respeito da resolução que havia apresentado. Desse modo, ao questioná-lo, pretendíamos provocar um "desequilíbrio na sua estrutura cognitiva, fazendo-a avançar no sentido de uma nova e mais elaborada reestruturação" (MOYSÉS, 1997, p. 37).

Nesse sentido, a ação de "corrigir" a resolução do estudante não se resumiu na simples indicação do erro e consequente substituição pela resposta correta. Ao contrário, o questionar foi um meio de os estudantes autorregularem seu processo de aprendizagem, dando pistas para corrigirem possíveis equívocos e prosseguirem na resolução.

Tomando as resoluções dos estudantes às questões propostas como um tipo de comunicação "que se pretende compreender para além de seus significados imediatos" (BARDIN, 1977, p.29), pareceu-nos útil recorrer à Análise de Conteúdo enquanto estratégia metodológica para nossa investigação. Considera-se Análise de Conteúdo como um

\footnotetext{
"Conjunto de técnicas de análise das comunicações visando obter, por procedimentos, sistemáticos e objetivos de descrição do conteúdo das mensagens, indicadores (quantitativos ou não) que permitam a inferência de conhecimentos relativos às condições de produção/recepção (variáveis inferidas) destas mensagens (BARDIN, 1977, p.42)."
}

Organizamos nossa investigação buscando indícios que permitissem inferir se esses questionamentos de algum modo contribuíram nesse sentido. Para tal, organizamos um "mapa" 
que nos permitiu identificar em quais questões havia um maior número de alteração nas resoluções ao longo das fases da prova. A partir disso, organizamos agrupamentos, indicados por G1, G2, etc, tomando como ponto de corte o procedimento adotado pelo estudante para resolver a questão. Consideramos "estratégia como a maneira pela qual o estudante abordou o problema, (...) já o procedimento relaciona-se ao processo de desenvolvimento da estratégia" (DALTO, 2007, p.28).

Para este artigo, escolhemos a Questão1 da prova, cujo enunciado e resolução esperada são mostrado na Figura 1.

Questão 1: Usando as razões trigonométricas, pode-se calcular distâncias e a altura de edifícios sem precisar subir neles. Para isso, uma pessoa de 1,62 $\mathrm{m}$ de altura posiciona-se a certa distância do prédio e vê o seu topo a um ângulo de $28^{\circ}$.

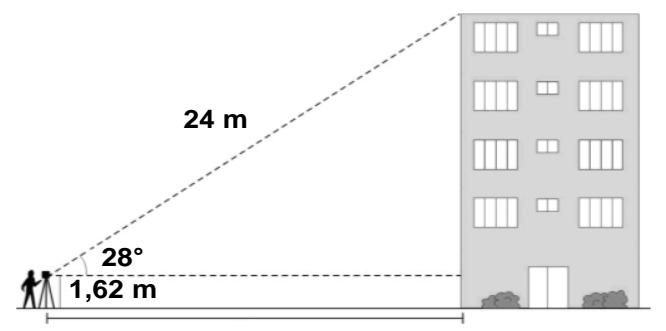

a) Usando as medidas que constam no desenho, qual é a altura aproximada do edifício?

b) A que distância essa pessoa encontra-se do prédio?

Resolução esperada:

a) Indicando por $d$ a altura vertical acima dos olhos da pessoa temos:

$$
\begin{gathered}
\operatorname{sen} 28^{\circ}=\frac{d}{24} \\
0,47=\frac{d}{24} \\
d=11,28
\end{gathered}
$$

A altura $h$ procurada será então dada por $h=11,28+1,62=12,9 m$

R. A altura é $12,9 m$.

b) Indicando por $x$ a distância da pessoa ao prédio temos:

$$
\begin{gathered}
\cos 28^{\circ}=\frac{x}{24} \\
0,88=\frac{x}{24} \\
x=21,12
\end{gathered}
$$

R. Essa pessoa encontra-se a $21,12 m$ do prédio.

Figura 1 -Questão 1 da prova e resolução esperada.

(Fonte: do autor)

DOI: Em andamento. 
Entendemos como estratégia para resolução desta questão a identificação da razão trigonométrica que permitia o cálculo da medida solicitada (no caso, o seno), e como procedimento o desenvolvimento de uma relação de proporcionalidade envolvendo o seno de $28^{\circ}$ e as medidas constantes na figura.

\section{Análise dos dados}

Os agrupamentos definidos com base nas resoluções apresentadas pelos estudantes são mostrados no Quadro 1. Nele, utilizamos: i) um código de identificação formado pela letra $P$ (prova) seguido de uma numeração com dois dígitos $(01,02, \ldots, 25)$ segundo a ordem com que seus nomes apareciam no diário de classe da disciplina, ii) uma descrição dos procedimentos adotados pelos estudantes antes da terceira fase da prova, iii) os questionamentos apresentados ao lado de suas resoluções iv) os encaminhamentos nas fases subsequentes.

O G1 é formado pelas produções dos estudantes que resolveram corretamente a questão, ou seja, forneceram a resposta com a unidade adequada. Em G2 temos as produções nas quais se identifica corretamente a razão trigonométrica que resolve a questão, resolve corretamente a relação de proporcionalidade e se apresenta o resultado 11,28 como resposta à questão, com a unidade adequada. O G3 é formado por uma única produção, na qual se efetua o mesmo procedimento de $\mathrm{G} 2$, porém apresenta-se a resposta sem unidade.

Para esses três grupos, apresentou-se o questionamento "Todos os dados do problema foram utilizados em sua resolução?" buscando, por exemplo, instigá-los a: no caso de G1, reler para refletir sobre a resolução apresentada; para G2, levá-los a perceber que haviam se esquecido de adicionar a altura da pessoa; no caso de G3, perceber que havia uma unidade de medida especificada no enunciado (metros). Porém, foram poucos (apenas três) os estudantes desses três grupos que fizeram algum tipo de modificação em suas respostas.

Em G4 e G5, ambos formados por uma única produção, a estratégia desenvolvida pelos estudantes consistiu na identificação da razão trigonométrica adequada à obtenção da medida desconhecida. O procedimento de resolução adotado consistiu, primeiramente, na montagem uma relação de proporcionalidade substituindo o valor do seno de $28^{\circ}$, com aproximação de duas casas decimais. Na sequência, o estudante cuja produção faz parte de G4 realiza, equivocadamente, o produto dos meios da proporção, igualando esse valor ao quociente dos extremos. Em seguida, adiciona ao valor encontrado a altura da pessoa, fornecendo esse resultado como resposta ao problema, com a unidade adequada. Em G5, observamos o desenvolvimento de procedimento similar, porém também equivocado. Além disso, não explicita alguma resposta. Para os estudantes desses grupos, buscamos confrontá-los com suas próprias respostas, fazendo-os refletirem sobre o resultado que haviam encontrado ao resolver a relação de proporcionalidade. 
Tabela 1 - Agrupamentos construídos para a Questão 1.

\section{Grupo Provas Encaminhamento até a Questionamento Encaminhamento após a 3a fase \\ 3aㅡ fase}

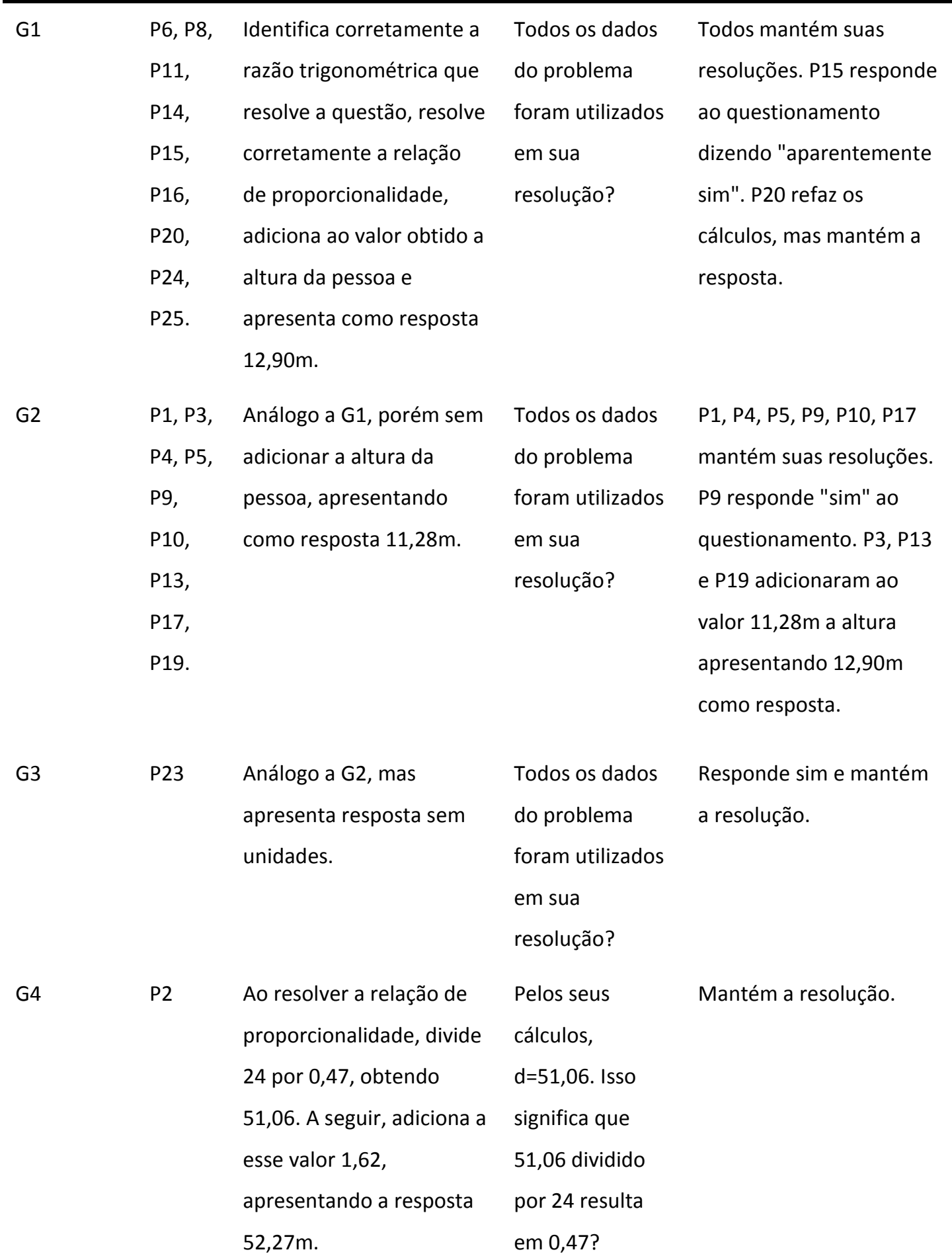

DOI: Em andamento. 
apresentando a resposta

$52,27 \mathrm{~m}$.

G6

G7

P18 Indica que $\cos 28=\mathrm{CO} / 24 \mathrm{e}$
obtém $\mathrm{CO}=21,6$. Não
apresenta resposta.

P12 Indica que seno é razão

do cateto oposto pela

hipotenusa, em seguida

$0,47=24 / x$ obtém $x=52,17$.

A seguir, adiciona a esse

valor 1,62 , apresentando

a resposta $53,79 m$.

\section{O que é o} cosseno de um ângulo? E o seno?
24 é a medida do cateto oposto a qual ângulo?
Mantém a resolução.

Mantém a resolução.

No caso de G4, o questionamento foi "Pelos seus cálculos, $d=51,06$. Isso significa que 51,06 dividido por 24 resulta em 0,47?", e para G5, "Seus cálculos mostram que d=0,025. Então 0,025 dividido por 24 é 0,46?" Nosso intuito era que percebessem o equívoco e o corrigissem. Ao analisar a produção desses estudantes nas etapas subsequentes, percebemos que nossa expectativa não foi alcançada. Nenhum deles apresentou algum tipo de alteração em suas resoluções, para essa questão.

Entretanto, no caso do estudante P2, que compõe o grupo G4, constamos que o mesmo tipo de equívoco foi cometido em outras cinco questões da prova (Q5, Q9(a), Q11, Q19 e Q21), todas elas tendo sido reelaboradas após a apresentação de questionamentos similares ao apresentado na questão 1 (Pelos seus cálculos, ...então...). Portanto, há indícios de que o questionamento apresentado ao lado da resolução do estudante contribuiu para a reelaboração do procedimento desenvolvido anteriormente.

O grupo G6 é também formado por uma única produção. A análise de sua produção escrita mostra que esse estudante mostra saber que o seno de um ângulo é a razão do cateto oposto a ele pela hipotenusa do triângulo retângulo ao qual pertence esse ângulo, e reconhece a utilização dessa razão trigonométrica permite obter a medida desconhecida. Entretanto, ao trabalhar na relação de proporcionalidade, atribui equivocadamente o valor 24 como medida do cateto oposto, quando na verdade trata-se da medida da hipotenusa. Na sequência, resolve 
corretamente a regra de três, e adiciona ao valor encontrado a altura da pessoa, fornecendo esse resultado como resposta ao problema, com a unidade adequada. Para esse estudante, ao questionar se 24 é cateto oposto a qual ângulo, buscávamos levá-lo a perceber seu equívoco, revendo essa etapa de sua resolução. Entretanto, isso não ocorreu.

Por fim, constitui o grupo G7 a produção de um estudante que resolveu a questão tomando como pressuposto que é o cosseno a razão entre o cateto oposto a um ângulo e a hipotenusa do triângulo retângulo ao qual pertence esse ângulo. Ao montar uma regra de três, toma como incógnita a medida do cateto oposto (indicado por $\mathrm{CO}$ ), e atribui o valor 24 à medida da hipotenusa. Na sequência, resolve corretamente a regra de três, obtendo que $C O=21,6$, mas não explicita algum tipo de resposta. Buscando levá-lo a perceber seu equívoco, questionamos "O que é o cosseno de um ângulo? E o seno?".

$\mathrm{Na}$ verdade, equívocos como esse foram recorrentes em diversas outras questões do mesmo estudante. Ainda no item (b) da questão 1, toma o seno como a razão entre o cateto adjacente a um ângulo e o cateto oposto a esse mesmo ângulo. Já em Q5, toma o seno como a razão entre o cateto oposto a um ângulo e a hipotenusa do triângulo retângulo ao qual pertence esse ângulo, porém em lugar de tomar a medida do cateto, toma a medida do cateto adjacente ao montar uma regra de três. Em Q8, toma a medida da hipotenusa em lugar do cateto oposto. Já em Q11 chega a utilizar, na mesma questão, tanto o seno quanto o cosseno como sendo a razão entre cateto adjacente e cateto oposto. Mesmo sendo questionado se "Seno e cosseno de um ângulo são a mesma coisa?", não modificou nenhuma de suas resoluções.

\section{Reflexões finais}

Buscamos neste artigo tecer reflexões sobre a utilização de um instrumento de avaliação, a prova em fases, em aulas de Matemática em uma turma do Ensino Médio. Nossa expectativa inicial era que os questionamentos apresentados ao lado das resoluções, entre a terceira e quarta fases, possibilitariam ao estudante uma reflexão acerca da resolução que havia sido apresentada. Imaginamos que os questionamentos apresentados provocariam um desequilíbrio na sua estrutura cognitiva do estudante fazendo-o avançar no sentido de uma nova e mais elaborada estruturação de sua resolução.

Ao analisar sua produção escrita, deparamo-nos com situações que evidenciam como foram dúbios os questionamentos que apresentamos ao lado de suas resoluções. Sentimos grande dificuldade em formulá-los de modo que "chamassem a atenção" dos estudantes para os erros e possibilitassem a correção dos mesmos. Entendemos que aprimorar essa "arte de fazer perguntas" torna-se essencial quando se pensa em tornar formativo esse instrumento de avaliação. 
Percebemos também que grande parte das questões que compuseram a prova eram tarefas rotineiramente resolvidas sempre da mesma maneira, seguindo o mesmo procedimento passo-a-passo. Tal fato evidenciou como estávamos "imersos" em uma prática tradicional que se refletiu na escolha que fizemos para compor as questões da prova, mostrando assim que buscar alternativas à elaboração dessas questões é fundamental quando se pensa em tomar a avaliação como prática de investigação e oportunidade de aprendizagem.

Assim, se buscamos fazer da prova em fases um instrumento de avaliação formativa, com finalidade pedagógica e objetivo de "contribuir para melhorar a aprendizagem em curso, informando o professor sobre as condições em que está a decorrer essa aprendizagem, e instruindo o aprendente sobre o seu próprio percurso, os seus êxitos e as suas dificuldades" (HADJI, 1994, p. 63), devemos pensar que, antes de mais nada, ela ofereça ao professor indicativos para rever sua prática pedagógica e adaptar suas estratégias de ensino.

Em nossa pesquisa, o instrumento prova escrita havia sido modificado, porém sua própria "estrutura" carregava uma visão tradicional de avaliação. Além de repensar o instrumento, fica evidente a necessidade de repensar a própria prática avaliativa, numa busca constante de completá-la, modificá-la e aperfeiçoá-la (BARLOW, 2006).

\section{Referências}

BARLOW, M. Avaliação escolar: mitos e realidades. Porto Alegre: Artmed, 2006.

DE LANGE, J. Mathematics, Insight and Meaning. Utrecht: OW \&OC, 1987.

Framework for classroom assessment in mathematics. Madisons: WCER, 1999. Disponível em: <http://www.fi.uu.nl/publicaties/literatuur/6279.pdf>. Acesso em: 15 maio 2010.

FREUDENTHAL, H. Mathematics as an Educational Task. Dordrecht: Reidel Publishing Company, 1973.

Learning processes. Lecture at the Pre-session of the NCTM meeting Boston, 18 April 1979.

HADJI, C. A avaliação, regras do jogo. 4.ed. Portugal: Porto, 1994.

MOYSÉS, L. Aplicações de Vygotsky à educação matemática. Campinas: Papirus, 1997.

VAN DEN HEUVEL-PANHUIZEN, M. V. D. Assessment and Realistic Mathematics Education. Utrecht: CD-ß Press/Freudenthal Institute, Utrecht University. 1996.

VIOLA dos SANTOS, J. R.; BURIASCO, R. L. C. de; CIANI, A. B. A Avaliação como Prática de Investigação e Análise da Produção Escrita em Matemática. Revista de Educação (PUCCAMP), v. 25, p. $35-45,2008$. 
André Luis Trevisan. Bacharel em Matemática Aplicada e Computacional e licenciado em Matemática, mestre em Matemática Aplicada pela Universidade Estadual de Campinas e doutor em Educação Matemática pela Universidade Estadual de Londrina. Professor da Universidade Tecnológica Federal do Paraná, câmpus Londrina. E-mail: andrelt@utfp.edu.br.

Regina Luzia Corio De Buriasco. Licenciada em Matemática pela Faculdade de Filosofia Ciências e Letras de Santo André, mestre em Educação Matemática pela Universidade Estadual Paulista Júlio de Mesquita Filho e doutora em Educação pela Universidade Estadual Paulista Júlio de Mesquita Filho. Docente da Universidade Estadual de Londrina e Programa de Pós-Graduação em Ensino de Ciências e Educação Matemática. Bolsista Produtividade do CNPq. Email: reginaburiasco@gmail.com 